\title{
ANTIOXIDANT, METABOLIC AND ANTITUMOR ACTIVITY OF TRITERPENOIDS COMBINATION WITH CYTOSTATICS
}

\author{
OLGA VOROBYOVA ${ }^{a}$, ELIZAVETA GRUBOVA ${ }^{a}$, KSENIYA BELYAEVA ${ }^{b}$, ANNA SOLOVYEVA $^{b}$, NADEZHDA $^{2}$ \\ PLOTNIKOVAc, OLGA DERYABINAc, NINA MELNIKOVA ${ }^{a^{*}}$
}

\begin{abstract}
${ }^{a}$ Department of Pharmaceutical Chemistry, Federal State Budgetary Educational Institution of Higher Education "Privolzhsky Research Medical University", Ministry of Health of the Russian Federation, Minin sq., 10/1, 603005 Nizhny Novgorod, Russia, $b$ Laboratory of Experimental Medicine, Federal State Budgetary Educational Institution of Higher Education "Privolzhsky Research Medical University", Ministry of Health of the Russian Federation, Minin sq., 10/1, 603005 Nizhny Novgorod, Russia, ${ }^{c}$ Medicine Institute, N. P. Ogarev Mordovian State University, Bolshevistskaya St. 68,430005 Saransk, Russia

Email: melnikovanb@gmail.com
\end{abstract}

Received: 11 Dec 2019, Revised and Accepted: 29 Jan 2020

\section{ABSTRACT}

Objective: To study the effect of betulin derivatives combination with 5-fluorouracil or hydrazine sulfate on the ROS generation, the SOD and LDH activity using rat blood, as well as the effect of combination drugs on Ehrlich carcinoma in experiments on mice.

Methods: We used a chemiluminescence technique to study the ROS generation, and spectrophotometry to determine the MDA level and the SOD and LDH activity. The model of transplanted Ehrlich ascites carcinoma was investigated on mice using a cytological analysis of ascitic fluid cells according to Pappenheim`s method.

Results: In vitro experiments on rat blood at the doses of 2, 5 and $10 \mu \mathrm{g}$ per ml revealed the dose-dependent effect of combination drugs on the antioxidant properties. In plasma, the ROS generation and the MDA level increased by $10-300 \%$ in comparison with control at the doses of 5 and 10 $\mu \mathrm{g}$ per $\mathrm{ml}$ only. Still, the SOD and LDH activity in general increased by $10-130 \%$ in comparison with control under the action of the studied combination drugs. The study on mice showed the effectiveness of a combination of triterpenoids and cytostatics in Ehrlich ascites carcinoma therapy. The state and behavior of the animals improved, the volume of ascites fluid decreased by $40-50 \%$ after treatment for $10 \mathrm{~d}$.

Conclusion: The combination of betulin derivatives with cytostatics can be used as antitumor drugs in Ehrlich ascites carcinoma therapy that is due to metabolic plasticity, increased ROS generation in enhanced antioxidant enzyme protection.

Keywords: Ehrlich carcinoma, Betulin-3,28-diacetate, Betulonic acid, Hydrazine sulfate, 5-fluorouracil, Antioxidant properties

(c) 2020 The Authors. Published by Innovare Academic Sciences Pvt Ltd. This is an open-access article under the CC BY license (http://creativecommons.org/licenses/by/4.0/) DOI: http://dx.doi.org/10.22159/ijpps.2020v12i3.36608. Journal homepage: https://innovareacademics.in/journals/index.php/ijpps

\section{INTRODUCTION}

The high toxicity and many undesirable side effects of anticancer drugs are one of the problems in tumor treatment because it leads to patients' life quality deterioration. In this regard, some novel chemotherapy that will enable to a reduction of anticancer drug doses and side effects is needed.

The most promising approach in therapy is the use of natural substances with cytotoxic activity concerning tumor cells but not affecting healthy ones. Such substances include lupane triterpenoids-betulin, betulinic and betulonic acids and their derivatives [1-7]. Recent studies have shown that the combination of triterpenoids such as oleanolic, ursolic and betulinic acids with 5-fluorouracil might be a useful tool with reduced doses of an anticancer drug-5-fluorouracil and without any side effects. Triterpenoids are able to potentiate the 5-fluorouracil effect by affecting different stages of esophageal carcinoma and other tumors [8, 9]. Previously, we showed the animals state improvement indicated by survival, body weight, wool, behavior, reduced cardiotoxicity when Ehrlich carcinoma was treated by the combination of 5-fluorouracil or hydrazine sulfate with betulin-3,28-diphosphate in in vivo experiment [10]. The effect may be due to the decreased dose of high toxic cytostatics and increased metabolic processes in an animal body, including antioxidant enzyme protection and energy metabolism activation. Hydrazine sulfate is an insufficiently explored antitumor agent; it inhibits monoamine oxidase and blocks gluconeogenesis by phosphoenol-pyruvate carboxylase [11]. 5-fluorouracil inhibits thymidylate synthase, disrupts the synthesis of the nuclear acids resulting in the apoptosis of tumor cells [12].

The generation of reactive oxygen species (ROS) in tumor cells is one of the reasons for apoptosis onset, which does not depend on an apoptotic mechanism. Therefore, when developing new drugs, it is necessary to take into account the balance of antioxidant and prooxidant properties, the ROS generation, as well as the SOD, catalase and glutathione peroxidase activity.

Another essential reason for apoptosis is the change of energy metabolism-mainly glycolysis and oxidative phosphorylation in a tumor cell, that can be assessed by the lactate dehydrogenase activity. The influence of drugs on these processes in cancer cells and healthy cells is an object of intensive research. There been discussed the predominance of active glycolysis (Warburg effect) or oxidative phosphorylation (Warburg reversal effect) in the growth of tumor cells. It has been demonstrated that metabolic plasticity the transformation of glycolysis to oxidative metabolism in in vitro experiments can be observed in tumors. Due to the decrease of mitochondrial oxidative phosphorylation, less reactive oxygen species are generated, they being cytotoxic to cancer cells [13].

The present study considers the antioxidant and metabolic properties in in vitro experiments, and antitumor activity of the combination drugs of betulin-3,28-diacetate and betulonic acid with cytostatics (5-fluorouracil and hydrazine sulfate) on mice.

The influence of betulin derivatives on the competition of these processes is important. At the same time, there are no data on the inhibition or activation of glycolysis and phosphorylation under these compound's action. In this work we studied ROS generation in Fenton reaction using chemiluminescence, evaluation of the MDA level and the SOD activity, the assessment of the LDH catalytic activity in direct and reverse reactions in plasma and erythrocytes. Antitumor activity was studied on the transplanted Ehrlich ascites carcinoma model in mice using the data on cytological analysis, the volume of ascitic fluid, and the state of animals. 


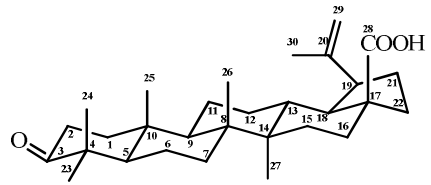

Betulonic acid (BA)

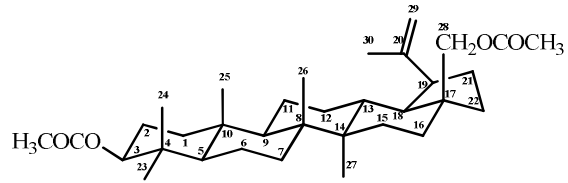

Betulin-3,28-diacetate (BDA)<smiles>O=c1[nH]cc(F)c(=O)[nH]1</smiles>

5-fluorouracil (5-FU)
$\mathrm{H}_{2} \mathrm{~N}-\mathrm{NH}_{2} \cdot \mathrm{H}_{2} \mathrm{SO}_{4}$

Hydrazine sulfate (HS)

Fig. 1: Formulas of combination drugs components

\section{MATERIALS AND METHODS}

\section{Materials}

Betulin was isolated from Betula Pendula bark. The Betula Pendula Roth bark was obtained from Bor forestry of the Nizhny Novgorod region, the samples of the bark were compared with ones obtained from the Biocollections of the VILAR Botanical Garden (voucher specimen No. 68 from 16 July 2017). Betulin was extracted from the bark by methyl tert-butyric ester (3 times) and then combined mixture heated up to $55{ }^{\circ} \mathrm{C}$ during $4 \mathrm{~h}$. After solvent removing a residue was treated by an aqueous solution of $1 \% \mathrm{NaOH}$ at boiling during $1 \mathrm{~h}$ and then washed by water. Finally, betulin was recrystallized (ethanol). 5-fluorouracil was purchased from Sigma Aldrich (Moscow, Russia), hydrazine sulfate was purchased from Sigma Aldrich (Moscow, Russia). Purified water (resistivity $\geq 18$ $\mathrm{M} \Omega \cdot \mathrm{cm}$, Millipore, Merck, Darmstadt, Germany), water for injections, ethanol 96\%, Tween 80, ascorbyl palmitate (Sigma Aldrich, Moscow, Russia), peach oil were used.

Betulin-3,28-diacetate (BDA) and betulonic acid (BA) were synthesized according to the methods described in $[14,15]$, respectively. Spectral data were the following: FTIR of BDA $\left(v, \mathrm{sm}^{-1}\right)$ : $2943\left(\mathrm{CH}_{3}, \mathrm{CH}_{2}, \mathrm{CH}\right), 1728$ (C=0), 1033 (C-O); ${ }^{13} \mathrm{C}-\mathrm{NMR}$, ppm: 79.95 (C-3), 61.56 (C-28), 170.66 (COAc), 171.6 (COAc); 99.9\% (HPLC). FTIR of BA $\left(v, \mathrm{sm}^{-1}\right): 3413(\mathrm{O}-\mathrm{H}), 1705(\mathrm{C}=0), 1643(\mathrm{C}=\mathrm{C}), 883$ $\left(=\mathrm{CH}_{2}\right)$; ${ }^{13} \mathrm{C}-\mathrm{NMR}, \mathrm{ppm}: 216.5$ (C-3), 177.3 (C-28), 150.3 (C-20), 109.5 (C-29); 99.8\% (HPLC).

\section{Biological activity}

Male mice (20-30 g) and male Wistar rats (200-250 g) were purchased from the Animal Breeding Facilities "Stolbovaya" (Chekhov, Moscow region, Russia). The animals were studied according to the criteria outlined by European Convention ET/S 129, 1986 and directives 86/609 ESC. The animals were handled humanely, kept in plastic suspended cages, and placed in a wellventilated and clean rat house under suitable conditions at room temperature $\left(27 \pm 2{ }^{\circ} \mathrm{C}\right)$ and humidity. They were given food and water ad libitum and subjected to a natural photoperiod of $12 \mathrm{~h}$ light and $12 \mathrm{~h}$ dark cycle. The animals were allowed two weeks of acclimatization before starting all animal model experiments.
All tumor implantations, blood collections, and sacrifices were performed under anesthesia, all efforts being made to minimize suffering.

The Local Ethics Committee of Privolzhsky Research Medical University (Russian Federation) approved the study, Protocol No. 16 from 11 April 2018.

\section{Biological activity in vitro}

Biological activity in vitro was studied using rat blood stabilized with sodium citrate. Erythrocytes were washed twice with $0.9 \% \mathrm{NaCl}$ by centrifugation for $10 \mathrm{~min}$ at $1600 \mathrm{~g}$. Suspensions of $0.01 \%$ betulin or betulin derivative (betulin-3,28-diacetate, betulonic acid) and their mixtures with cytostatics were added to the whole blood $(1 \mathrm{ml})$ at the doses of 2,5 , and $10 \mu \mathrm{g}$ per ml. The ROS generation was evaluated by chemiluminescent intensity due to the Fenton reaction. The lipid peroxidation intensity (LPO) was estimated by the MDA level in plasma and erythrocytes by Uchiyama and Mihara methods [16]. Superoxide dismutase activity (EC1.15.1.1) was measured in erythrocytes using inhibition of adrenaline auto-oxidation [17]. The catalytic activity of lactate dehydrogenase (LDH, EC 1.1.1.27) was studied in the direct ( $\mathrm{LDH}_{\text {direct, }}$ substrate- $50 \mathrm{mmol}$ sodium lactate) and reverse $\left(\mathrm{LDH}_{\text {reverse, }}\right.$ substrate- $23 \mathrm{mmol}$ sodium pyruvate) reactions [18]. The specific activity of the enzymes was calculated from the protein concentration analyzed by the modified Lowry method [19].

\section{Biological activity in vivo}

Transplanted Ehrlich ascites carcinoma (EAC) was studied on mice in the experiment. $1 \mathrm{ml}$ of EAC cells containing $1 \times 10^{7}$ cells was transplanted into the abdominal cavity of a mouse. On day six after transplantation, the resulting ascites liquid was collected. The cells were precipitated at $400 \mathrm{~g}$, thrice washed by $0.15 \mathrm{M} \mathrm{NaCl}$ solution, and transplanted into the abdominal cavity of another mouse. Tumor cells were transplanted 2-3 times for cell culture recovery and standardization. The control tumor carrier mouse was prepared after the last transplantation and on day six after transplantation, its cells were used in the experiment. The tumor cells were thrice washed in saline and transplanted into the abdominal cavity of the experimental mice $\left(0.8 \mathrm{ml}, 1 \times 10^{7} \mathrm{cells} \cdot \mathrm{ml}^{-1}\right)$.

Table 1: The characteristic of animal experimental groups

\begin{tabular}{ll}
\hline Control group & Intact mice \\
\hline Control EAC group & EAC-bearing mice \\
EAC-5-FU group & EAC-bearing mice treated with 5-fluorouracil (5-FU) \\
EAC-HS group & EAC-bearing mice treated with hydrazine sulfate (HS) \\
EAC-(BA+5-FU) group & EAC-bearing mice treated with the combination drug of BA with 5-fluorouracil (5-FU) \\
EAC-(BA+HS) group & EAC-bearing mice treated with the combination drug of BA with hydrazine sulfate (HS) \\
EAC-(BDA+5-FU) group & EAC-bearing mice treated with the combination drug of BDA with 5-fluorouracil (5-FU) \\
EAC-(BDA+HS) group & EAC-bearing mice treated with the combination drug of BDA with hydrazine sulfate (HS) \\
\hline
\end{tabular}

Abbreviations: EAC-Ehrlich ascites carcinoma, BA-belulonic acid, BDA-betulin-3,28-diacetate. Note: The treatment of animals was carried out once a day intraperitoneally (i. p.). 


\section{Experimental protocol}

Male albino mice were divided into 8 groups, 10 animals $(n=10)$ in each group (table 1).

On day 11, all the mice were sacrificed by decapitation under anesthesia (Zoletil $60 \mu \mathrm{g} \cdot \mathrm{kg}^{-1}$ "Virbac Sante Animale", Vauvert, France; Xyla $6 \mathrm{mg} \cdot \mathrm{kg}^{-1}$, Interchemie, Venray, The Netherlands). On day 11 the ascitic fluid in the peritoneal cavity was carefully collected into plastic tubes by injecting the abdominal cavity, and then from the opened abdominal cavity with scissors under anesthesia and then kept in an ice-cold bath. The volume of the fluid was measured using a graduated centrifuge tube. The cytological analysis of the ascitic fluid cells was made according to Pappenheim`s method with azure-eosin staining and fixation with a $10 \%$ formalin solution [20]. $0.2 \mathrm{ml}$ of the drug, which contains 1.0 $\mathrm{mg}$ of BA or $1.2 \mathrm{mg}$ of BDA, was used. The dose of 5-FU and HS was $0.32 \mathrm{mg}$ per mouse. Compositions of the used dosage forms are shown in table 2. In contrast to BA combined dosage form, the cytostatic aqueous solution and BDA oil solution were administrated separately in case of BDA dosage form.

Table 2: Drugs compositions

\begin{tabular}{llll}
\hline Group & Cytostatic & Triterpenoid ${ }^{* *}$ & Excipients \\
\hline EAC-5-FU & $5-\mathrm{FU}^{*}-48 \mathrm{mg}$ & - & Water for injections-20.4 ml \\
EAC-HS & $\mathrm{HS}^{*}-48 \mathrm{mg}$ & - & Water for injections-30 ml \\
EAC-(BA+5-FU) & $5-\mathrm{FU}^{*}-64 \mathrm{mg}$ & $200 \mathrm{mg}$ & $\begin{array}{l}\text { Ethanol } 96 \%-4 \mathrm{ml} \\
\text { Tween } 80-4 \mathrm{~g}\end{array}$ \\
& & & Water for injections-32 $\mathrm{ml}$ \\
& & & Ethanol $96 \%-4 \mathrm{ml}$ \\
EAC-(BA+HS) & HS*-64 mg & $200 \mathrm{mg}$ & Tween $80-4 \mathrm{~g}$ \\
& & & Water for injections-32 ml \\
BDA & - & Ascorbyl palmitate-20 ml, peach oil-200 ml \\
\hline
\end{tabular}

*The amount of cytostatic agent contained in $0.2 \mathrm{ml}$ of the composition solution for i. p. administration corresponded to the dose of $15 \mathrm{mg} / \mathrm{kg}$ per day for 5 -fluorouracil and $16 \mathrm{mg} / \mathrm{kg}$ per day for hydrazine sulfate, ${ }^{* *}$ The amount of triterpenoid contained in $0.2 \mathrm{ml}$ of the composition solution for i. p. administration corresponded to the dose of $50 \mathrm{mg} / \mathrm{kg}$ per day.
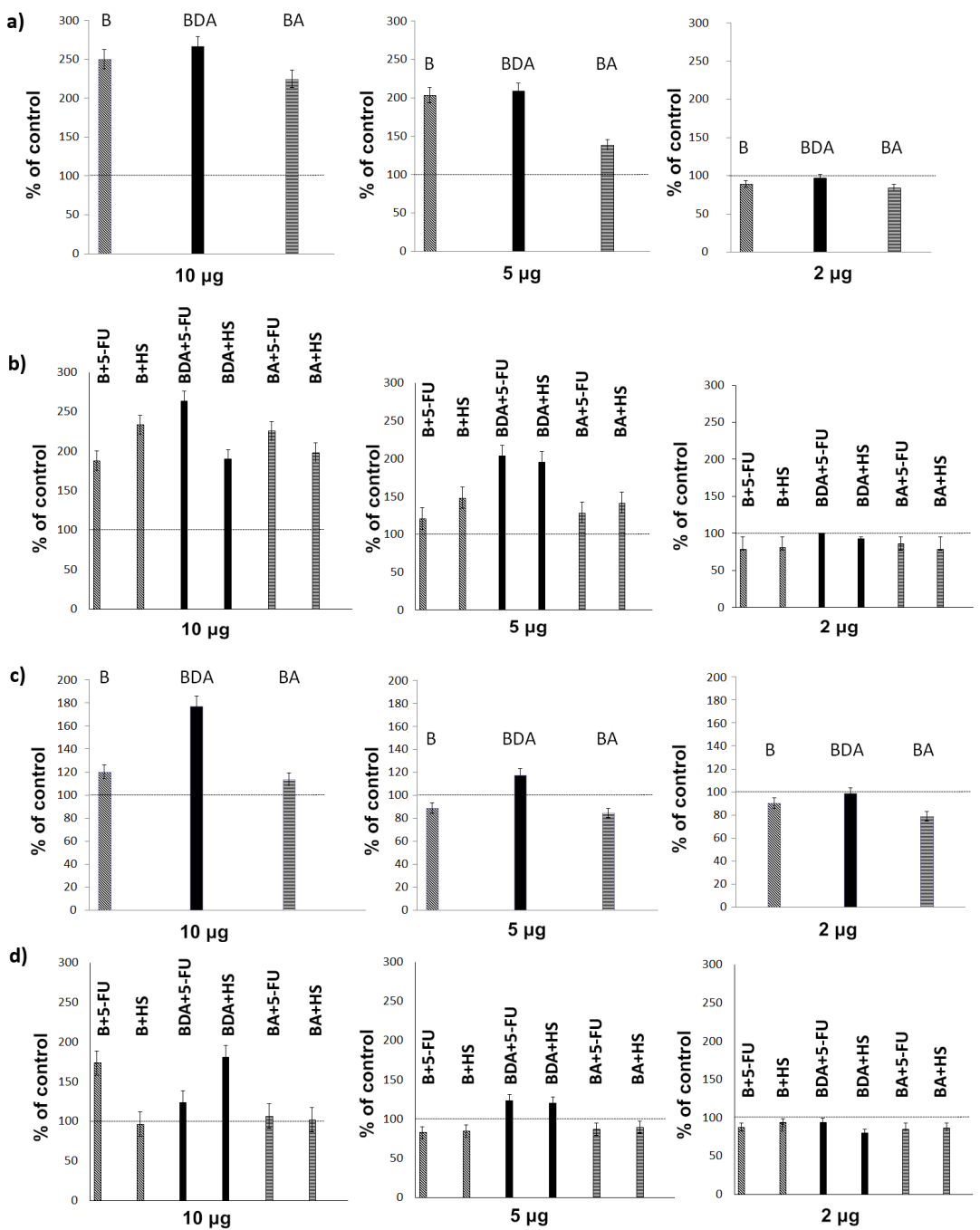

Fig. 2: Chemiluminescent intensity level under the action of triterpenoids and combination drugs with cytostatics at the doses of 2,5 and $10 \mu \mathrm{g}$ per $\mathrm{ml}$ in plasma $(\mathrm{a}, \mathrm{b})$ and in erythrocytes $(\mathrm{c}, \mathrm{d})$ as $\%$ of control $(\rho<0.05)$. Values are means \pm standard deviation $(\mathrm{n}=3)$ 


\section{Statistical analysis}

Biological activity in vitro was carried out in triplicates. Biological activity in vivo was carried out ten times in each group. The results expressed as mean \pm standard deviation. Data were analyzed using Microsoft Excel.

\section{RESULTS}

Antioxidant properties of betulin derivatives and their combinations with cytostatic in plasma and erythrocytes in vitro experiment on rats.

Antioxidant and metabolic activities of triterpenoids-betulin (B), betulonic acid (BA), betulin-3,28-diacetate (BDA), and their combinations with cytostatics $(\mathrm{B}+5-\mathrm{FU}, \mathrm{B}+\mathrm{HS}, \mathrm{BA}+5-\mathrm{FU}, \mathrm{BA}+\mathrm{HS}$, $\mathrm{BDA}+5-\mathrm{FU}, \mathrm{BDA}+\mathrm{HS}$ ) at the doses of 10,5 and $2 \mu \mathrm{g}$ per $\mathrm{ml}$ by nontumor rat blood were studied in comparison with the control rat blood without treatment taken as $100 \%$.

The level of chemiluminescent intensity after Fenton reaction both in plasma and erythrocytes was the dose-dependent as well triterpenoids as the combination of triterpenoids with cytostatics (fig. 2 a, b).

The ROS generation at the doses of 10 and $5 \mu \mathrm{g}$ per ml only increased but did not change at the low doses ( $2 \mu \mathrm{g}$ per $\mathrm{ml}$ ) under the action of both: triterpenoids as well as triterpenoids combinations with cytostatics.

The malondialdehyde (MDA) level as a biochemical index of lipoperoxidation under the action of B, BA and BDA increased at the dose of 5 and $10 \mu \mathrm{g}$ per $\mathrm{ml}$ in plasma only. In contrast, the index did not significantly change in erythrocytes (fig. $3 \mathrm{a}, \mathrm{b}$ ).
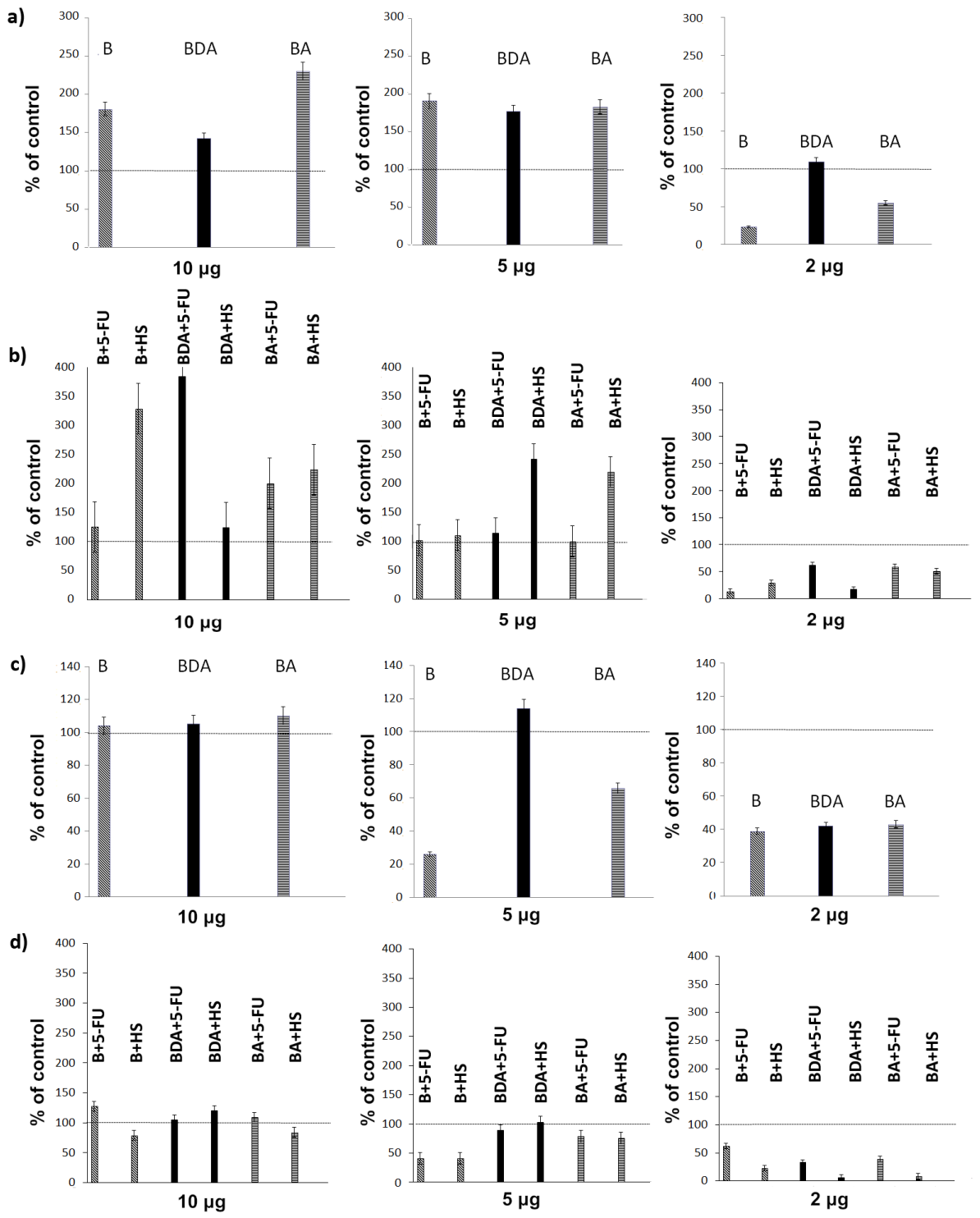

Fig. 3: MDA level in plasma (a, b) and in erythrocytes (c, d) under the action of triterpenoids and combination drugs at the doses of 2,5 and $10 \mu \mathrm{g}$ per $\mathrm{ml}$ as $\%$ of control $(\rho<0.05)$; malonic dialdehyde (MDA) plasma $-0.81433 \mu \mathrm{mol}^{-1} \cdot \mathbf{1}^{-1}$; (MDA) erythrocyte $-5.97700 \mu \mathrm{mol} \cdot \mathrm{l}^{-1}$. Values are means \pm standard deviation $(n=3)$

In contrast to these data, the MDA level decreased in response to triterpenoids and their combinations with cytostatics at the dose of $2 \mu \mathrm{g}$, except for BDA in plasma.
An antioxidant effect in relation to lipoperoxidation was most pronounced when HS was used as a dosage form component, a reduced MDA level in erythrocytes being 78-95\% at the low doses. 
The MDA level in erythrocytes decreased by 39-68\% under the action of 5-fluorouracil containing low-dosage forms.

The superoxide dismutase (SOD) activity in response to the action of betulin (B), betulonic acid (BA) and betulin-3,28-diacetate (BDA) was dose-dependent, but the SOD activity increased under the action of each triterpenoid at all doses. The effect of hydrazine sulfate (HS) on the SOD activity of combination drugs (B+HS, BA+HS and $\mathrm{BDA}+\mathrm{HS}$ ) was the same as that of single triterpenoids, and the SOD activity increased by $70-86 \%$ at the dose of $2 \mu \mathrm{g}$ per ml. The result corresponded to the-MDA level decrease in plasma and erythrocytes (fig. 4).
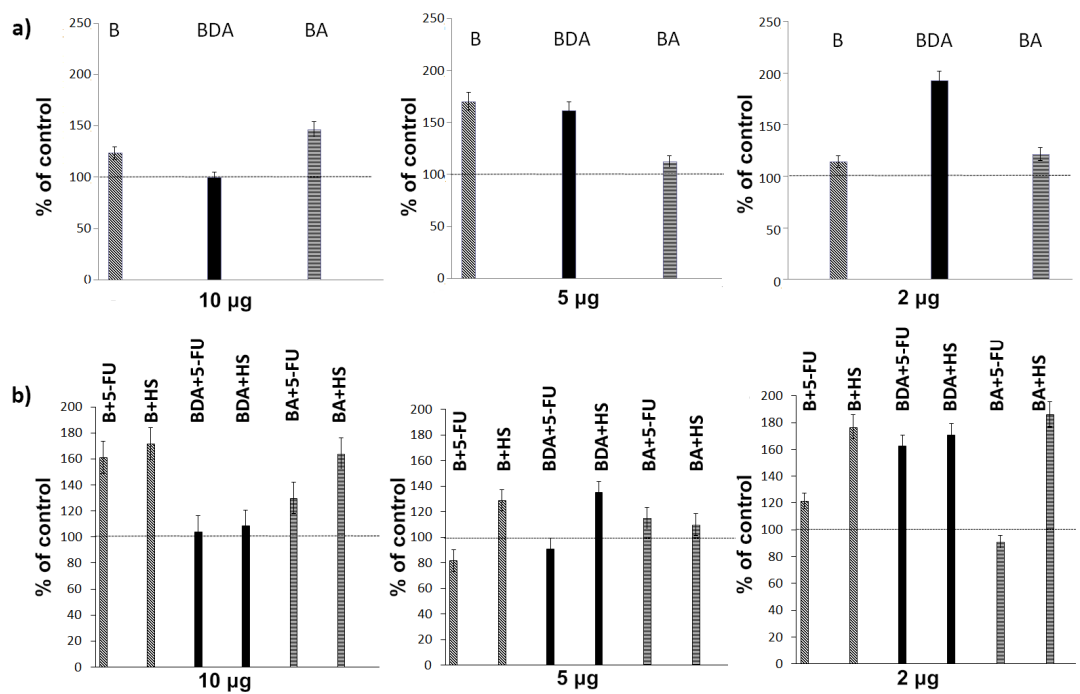

Fig. 4: The SOD activity of triterpenes (a) and combination drugs (b) at the doses 2,5 and $10 \mu \mathrm{g}$ per $\mathrm{ml}$ as $\%$ of control ( $\rho<0.05$ ); SOD996.95 $\mathrm{RU} / \mathrm{mg}$ protein. Values are means \pm standard deviation $(\mathrm{n}=3)$

A stable and significant increase in the SOD activity under the influence of the combination drugs of 5-fluorouracil was manifested at the large $(10 \mu \mathrm{g})$ and small $(2 \mu \mathrm{g})$ doses (fig. 4).

In general, the SOD activity increase under the action of the studied drugs shows that the components of the dosage forms containing triterpenoids can improve enzyme antioxidant protection.

Energy metabolism in a cell was evaluated by the lactate dehydrogenase (LDH) activity, which is an enzyme in anaerobic glycolysis in tumor cells, in which LDH activity is increased compared to nontumor cells.

The effect of triterpenoids on the activity of $\mathrm{LDH}_{\text {direct }}$ and $\mathrm{LDH}_{\text {reverse }}$ was dose-dependent, the highest activity in a direct reaction being observed at the large dose $(10 \mu \mathrm{g})$, while at the doses of 5 and $2 \mu \mathrm{g}$ the $\mathrm{LDH}_{\text {direct }}$ activity was close to the control. The dependence of $\mathrm{LDH}_{\text {reverse }}$ activity on the structure and the dose of triterpenoids was more complicated. At the dose of $2 \mu \mathrm{g}$, the $\mathrm{LDH}_{\text {reverse }}$ activity increased in response to betulin, betulin-3,28-diacetate and betulonic acid by $51 \%$, $31 \%$ and 59\%, respectively, compared to the control. At the dose of 10 $\mu \mathrm{g}$ the $\mathrm{LDH}_{\text {reverse }}$ activity increased under the action of betulin and betulin-3,28-diacetate by $64 \%$ and $112 \%$, respectively, while under the effect of BA the $\mathrm{LDH}_{\text {reverse }}$ activity was close to the control.

The increase in the $\mathrm{LDH}_{\text {reverse }}$ activity under the action of triterpenoids promotes the increase of the lactic acid formed mainly by M-subunits of $\mathrm{LDH}\left(\mathrm{LDH}_{\text {reverse }}\right)$ indicating the improvement in energy metabolism in erythrocytes due to anaerobic oxidation, is favorable not only for healthy cells but also for tumor cells.

The increase in the LDH activity under the action of 5-fluorouracil was observed in both: direct and reverse reactions, except the $\mathrm{LDH}_{\text {reverse }}$ activity at a dose of $5 \mu \mathrm{g}$ (table 3 ). The most significant increase in $\mathrm{LDH}_{\text {direct }}$ activity was found for the combination of 5fluorouracil with BDA at the dose of $10 \mu \mathrm{g}$ (by 75\%). The $\mathrm{LDH}_{\text {reverse }}$ activity in response to 5 -fluorouracil increased by $100 \%$ at the dose of $2 \mu \mathrm{g}$, and its combination with BDA increased the level of $\mathrm{LDH}_{\text {reverse }}$ by $130 \%$ at the dose of $2 \mu \mathrm{g}$, and by $33 \%$ at the dose of 5 $\mu \mathrm{g}$, while at the dose of $10 \mu \mathrm{g} \mathrm{LDH}_{\text {reverse }}$ decreased by $20 \%$ compared with control.
The LDH activity increased in direct reaction at all doses both of betulin, betulonic acid and betulin-3,28-diacetate and that of their combinations with cytostatics (hydrazine sulfate and 5-fluorouracil) (table 3 ). In contrast, the $\mathrm{LDH}$ activity in a reverse reaction was dose-dependent under the action of cytostatics, triterpenoids and their combinations.

The $\mathrm{LDH}_{\text {reverse }}$ activity increased by $97 \%$ at the dose of $2 \mu \mathrm{g}$ and by $34 \%$ at the dose of $10 \mu \mathrm{g}$ when treated by pure HS compared to the control (table 3). The $\mathrm{LDH}_{\text {direct }}$ activity by the combination of HS with triterpenoids treatment was similar to that of the control group. Under the action of BA+HS combination drug, the $\mathrm{LDH}_{\text {reverse }}$ activity was higher than that of the control group: by $130 \%$ at the dose of 2 $\mu \mathrm{g}$, and the BDA+HS combination increased the $\mathrm{LDH}_{\text {reverse }}$ activity by $161 \%$ and by $40 \%$ at doses of 2 and $10 \mu \mathrm{g}$, respectively (table 3 ).

In general, it should be noted that the combination drugs of triterpenoids (B, BA and BDA) with cytostatics activated the LDH activity in both direct and reverse reactions with an insignificant predominance of a reverse reaction. The data differ from our early published data about the combination of betulin-3,28-diphosphate with hydrazine sulfate and 5-fluorouracil, according to which $\mathrm{LDH}_{\text {reverse }}$ activity was the most pronounced.

The characteristics of the triterpenoid dosage form in Ehrlich carcinoma treatment in mice

The development of combined dosage forms of betulonic acid and cytostatics (5-fluorouracil and hydrazine sulfate) was based on the findings of in vitro experiments. The formulations of the dosage forms were made, taking into account the $\mathrm{ED}_{50}$ value of the cytostatics and the known dose of betulinic acid [9] in mice, which was $1 \mathrm{mg}$ per mouse. Combination therapy with betulin-3,28diacetate was performed by oil BDA injections at the dose of $1.2 \mathrm{mg}$ per mouse, which corresponded to the same molar concentration of betulinic acid, and by separate administration of cytostatics.

The administration of a daily repeated dose of $0.2 \mathrm{ml}$ per mouse (1.0 $\mathrm{mg}$ of BA or $1.2 \mathrm{mg}$ of BDA and $0.32 \mathrm{mg}$ of cytostatics per mouse) for $11 \mathrm{~d}$ showed no abnormal behavioral responses. Mice treated only with cytostatics displayed significantly deteriorated health status 
(wool state, body weight, and behavior) than those in the control group or EAC-(BDP+5-FU) and EAC-(BDP+HS) groups.

After ten days of Ehrlich carcinoma treatment by combination drugs of betulonic acid and betulin-3,28-diacetate with 5-FU and HS, more than $83 \pm 5 \%$ of the animals in the experimental groups survived, while not more than $70 \pm 5 \%$ of the animals survived in the control groups EAC-5-FU and EAC-HS (table 4). At the same time, the state of mice improved by objective indicators (body weight, wool, behavior) compared to the control-EAC group.

Table 3: Dose-dependent effects of triterpenoids and its combination with cytostatics on the LDH activity in direct and reverse reactions

\begin{tabular}{|c|c|c|c|}
\hline & \multirow[t]{2}{*}{ Dose, $\mu \mathrm{g} \cdot \mathrm{ml}^{-1}$} & \multicolumn{2}{|c|}{$\%$ of control } \\
\hline & & $\mathbf{L D H}_{\text {direct }}$ & $\mathbf{L D H}_{\text {reverse }}$ \\
\hline \multirow[t]{3}{*}{ B } & 2 & $128 \pm 8$ & $151 \pm 6$ \\
\hline & 5 & $106 \pm 4$ & $105 \pm 8$ \\
\hline & 10 & $132 \pm 1$ & $164 \pm 3$ \\
\hline \multirow[t]{3}{*}{ BA } & 2 & $102 \pm 5$ & $159 \pm 4$ \\
\hline & 5 & $115 \pm 4$ & $109 \pm 5$ \\
\hline & 10 & $168 \pm 8$ & $91 \pm 3$ \\
\hline \multirow[t]{3}{*}{ BDA } & 2 & $117 \pm 12$ & $131 \pm 8$ \\
\hline & 5 & $117 \pm 3$ & $85 \pm 1$ \\
\hline & 10 & $207 \pm 5$ & $212 \pm 7$ \\
\hline \multirow[t]{3}{*}{$5-\mathrm{FU}$} & 2 & $124 \pm 2$ & $201 \pm 4$ \\
\hline & 5 & $102 \pm 4$ & $85 \pm 12$ \\
\hline & 10 & $115 \pm 13$ & $163 \pm 4$ \\
\hline \multirow[t]{3}{*}{$\mathrm{B}+5-\mathrm{FU}$} & 2 & $106 \pm 8$ & $131 \pm 3$ \\
\hline & 5 & $95 \pm 1$ & $92 \pm 10$ \\
\hline & 10 & $101 \pm 4$ & $203 \pm 5$ \\
\hline \multirow[t]{3}{*}{$\mathrm{BA}+5-\mathrm{FU}$} & 2 & $102 \pm 3$ & $128 \pm 4$ \\
\hline & 5 & $112 \pm 9$ & $134 \pm 1$ \\
\hline & 10 & $137 \pm 4$ & $62 \pm 8$ \\
\hline \multirow[t]{3}{*}{$\mathrm{BDA}+5-\mathrm{FU}$} & 2 & $104 \pm 5$ & $229 \pm 4$ \\
\hline & 5 & $120 \pm 3$ & $133 \pm 3$ \\
\hline & 10 & $175 \pm 4$ & $80 \pm 8$ \\
\hline \multirow[t]{3}{*}{ HS } & 2 & $124 \pm 2$ & $197 \pm 15$ \\
\hline & 5 & $136 \pm 1$ & $97 \pm 3$ \\
\hline & 10 & $164 \pm 6$ & $134 \pm 5$ \\
\hline \multirow[t]{3}{*}{$\mathrm{B}+\mathrm{HS}$} & 2 & $109 \pm 8$ & $206 \pm 3$ \\
\hline & 5 & $119 \pm 1$ & $125 \pm 8$ \\
\hline & 10 & $121 \pm 7$ & $64 \pm 4$ \\
\hline \multirow[t]{3}{*}{$\mathrm{BA}+\mathrm{HS}$} & 2 & $120 \pm 4$ & $230 \pm 13$ \\
\hline & 5 & $110 \pm 5$ & $84 \pm 1$ \\
\hline & 10 & $140 \pm 8$ & $103 \pm 3$ \\
\hline \multirow[t]{3}{*}{$\mathrm{BDA}+\mathrm{HS}$} & 2 & $111 \pm 3$ & $261 \pm 8$ \\
\hline & 5 & $120 \pm 8$ & $104 \pm 5$ \\
\hline & 10 & $124 \pm 1$ & $140 \pm 3$ \\
\hline
\end{tabular}

Values are means \pm standard deviation $(\mathrm{n}=3)$. Biochemical indexes were taken as $100 \%$ : $\mathrm{LDH}_{\text {direct }}-60.87 \mathrm{nmol} \mathrm{NADH} \cdot \mathrm{min}^{-1} \cdot \mathrm{mg}^{-1} \mathrm{protein} \mathrm{LDH}_{\text {reverse}}-$ $125.58 \mathrm{nmol} \mathrm{NADH} \cdot \mathrm{min}^{-1} \cdot \mathrm{mg}^{-1}$ protein. $\mathrm{LDH}$ : lactate dehydrogenase.

Table 4: The effects of betulonic acid (BA) and betulin-3,28-diacetate (BDA) in combination drugs on the biological parameters of EACbearing mice on day $11^{a}$

\begin{tabular}{|c|c|c|c|c|c|c|}
\hline \multirow[t]{2}{*}{ Group } & \multirow[t]{2}{*}{ Survival } & \multicolumn{2}{|c|}{ Body weight } & \multirow[t]{2}{*}{ Ascitic fluid (ml) on d 11} & \multirow[t]{2}{*}{ Tumour cells $^{b}$} & \multirow[t]{2}{*}{ Neutrophilc } \\
\hline & & d 1 & d 11 & & & \\
\hline Control EAC & $3 / 10$ & $23.1 \pm 0.6$ & $29.2 \pm 0.5$ & $6.0 \pm 0.3$ & ++ & +++ \\
\hline EAC-5-FU & $8 / 10$ & $21.8 \pm 0.7$ & $26.3 \pm 1.1$ & $4.0 \pm 0.5$ & + & ++ \\
\hline EAC-HS & $6 / 10$ & $22.3 \pm 0.6$ & $27.1 \pm 0.9$ & $4.5 \pm 0.4$ & + & ++ \\
\hline $\mathrm{EAC}-(\mathrm{BA}+5-\mathrm{FU})$ & $10 / 10$ & $23.1 \pm 0.5$ & $25.2 \pm 0.7$ & $2.3 \pm 0.2$ & - & + \\
\hline $\mathrm{EAC}-(\mathrm{BA}+\mathrm{HS})$ & $7 / 10$ & $21.9 \pm 0.8$ & $24.3 \pm 0.5$ & $2.5 \pm 0.1$ & + & ++ \\
\hline $\mathrm{EAC}-(\mathrm{BDA}+5-\mathrm{FU})$ & $7 / 10$ & $22.4 \pm 0.5$ & $25.4 \pm 0.8$ & $2.1 \pm 0.3$ & + & ++ \\
\hline $\mathrm{EAC}-(\mathrm{BDA}+\mathrm{HS})$ & $9 / 10$ & $23.2 \pm 0.6$ & $26.3 \pm 0.7$ & $2.3 \pm 0.4$ & - & + \\
\hline Control & $10 / 10$ & $24.5 \pm 0.4$ & $25.1 \pm 0.3$ & 0 & - & + \\
\hline
\end{tabular}

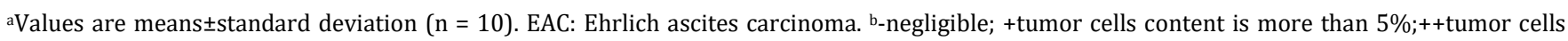
content is more than $10 \%{ }^{c}+$ neutrophil content corresponding to that of a healthy animal; ++neutrophil content is twice more than that of a healthy animal; +++neutrophil content is thrice more than that of a healthy animal.

On day 11 , the ascitic fluid was examined. The fluid volume in the control group was negligible, but that in the EAC-control group was very large. The amounts of the ascitic fluid in EAC-5-FU and EAC-HS groups were one and a half less than that of the EAC-control group. In contrast, the ascitic fluid volumes of combination drugs groups were thrice less than the volumes of EAC-control group on day 11.

Histological analysis showed that there were no significant changes in the heart tissues in EAC-(BA+5-FU) and EAC- $(\mathrm{BA}+\mathrm{HS})$ groups in contrast to the control-EAC group and BDA containing groups. The oleophilic dosage form with peach oil can explain the cardiotoxicity in BDA containing groups.

The content of neutrophils and tumor cells when treated by BA+5$\mathrm{FU}$ and BDA+HS combination drugs significantly decreased (table 4).

The cytological study of ascitic fluid after the treatment by the combination drugs $\mathrm{BDA}+\mathrm{HS}$ and $\mathrm{BA}+5-\mathrm{FU}$ showed no tumor cells, 
whereas tumor cells were found in control groups EAC-5-FU and EAC-HS.

\section{DISCUSSION}

Thus, it may be proposed that the capability of all studied triterpenoids and their compositions with cytostatics to activate the LDH activity in both direct and reverse reactions will lead to the apoptosis of tumor cells due to energy metabolism regulation. Oxidative processes can also cause an increase in tumor cell apoptosis under the action of combination drugs at the doses of 5 and $10 \mu \mathrm{g}$. The first process was due to the ROS excess in plasma shown by high chemiluminescence intensity and a high MDA level. The second process was manifested as an antioxidant effect in erythrocytes indicated by decreased chemiluminescence intensity and a decreased MDA level, as well as increased SOD activity.

Improvement of antioxidant biochemical indexes of blood during combined treatment by cytostatics with betulin derivatives is mainly due to the effect of triterpenoids. The similar ability of natural triterpenoids to exhibit antioxidant properties, reducing the level of lipid peroxidation in red blood cells and increasing the activity of superoxide dismutase in animals with grafted Ehrlich ascites carcinoma, has also been shown in other studies [21-24].

The inhibition of SOD and CAT activities as a result of tumor growth were also reported. Similar findings were observed in EAC bearing mice. It has been shown that a decrease in SOD activity in EAC bearing mice may be due to loss of $\mathrm{Mn}^{2+}$ containing SOD activity in EAC cells and the loss of mitochondria, leading to a decrease in total SOD activity in the liver [24, 25].

It was shown that the 5-FU treatment additionally decreased the SOD activity and resulted in about $30 \%$ inhibition of SOD activity in control and carcinoma-bearing mice [26]. The authors explained that these data could be due to the depression of $\mathrm{Cu}-\mathrm{Zn}$ SOD activity by oxidative stress provoked by a high dose of $\mathrm{H}_{2} \mathrm{O}_{2}$, similar to the inhibition of SOD activity by $\mathrm{CoCl}_{2}$. The authors explained this assumption with the proof that Co (II) binds stoichiometrically at the zinc site in the SOD protein and the Cu-Co SOD derivative has low enzymatic activity.

The decreased SOD activity was observed in various cancer conditions and diminished scavenging of free radicals formed in liver cancer conditions [27]. Our data also support a valuable property of betulin derivatives in the correction of the SOD activity in cancerous condition, in particular in Ehrlich ascites carcinoma treatment. The role of betulin derivatives as natural antioxidants obtained from birch bark extracts is not only the significant increase of the SOD levels and the MDA level decrease of EAC-bearing mice but also the decrease of cytostatics side effects. Moreover, the antitumor activity of betulin derivatives may be either through the induction of apoptosis or by inhibition of neovascularization $[4,5]$. The free radical hypothesis supported the fact that the antioxidants effectively inhibit the tumor, and the observed properties may be attributed to the antioxidant and antitumor principles present in the betulin contained dosage forms. Because the cells of different cancer types exhibit heterogeneity in the levels of oxidative stress, associated with various expression levels of SOD, the administration of combination forms of cytostatics with betulin derivatives at three different doses significantly increased the SOD level in a dose-dependent manner. The similar dose-dependent antioxidant effect was reported at the administration of methanol extract of Dregea volubilis leaves against EAC [22].

Some researchers consider the SOD level as a more critical protective factor against superoxide radicals, also generated as a by-product of oxidative phosphorylation [23]. Although there is no complete evidence of the mechanism of hydrazine sulfate action as a cytostatic agent, it is believed that its antitumor effect is mainly due to the accumulation of metabolic intermediates behind the phosphoenolpyruvate carboxykinase block [28]. It can be assumed that the effect of betulin and its derivatives in the treatment of hydrazine sulfate is likely to regulate the balance between glycolysis and oxidative phosphorylation.

\section{CONCLUSION}

The study has demonstrated the effectiveness of the combination of triterpenoids-betulin, betulonic acid, betulin diacetate, and antitumor components (hydrazine sulfate and 5-fluorouracil) in the treatment of Ehrlich ascites carcinoma in mice. The animals state and behaviour improved, their survival increased, the volume of ascitic fluid decreased by $40-50 \%$ during the treatment. There has been shown the dose-dependent effect of the drugs on biochemical blood indexes, which can be regarded as a prognostic factor in reducing the toxic cytostatic dose in the drug. These facts might lead to a new strategy for advanced inoperable carcinoma. Improved quality of animals 'life and a reduced dose of toxic cytostatics are the indicators to use combination drugs in palliative medicine.

\section{FUNDING}

Nil

\section{AUTHORS CONTRIBUTIONS}

Nina Melnikova has made the contribution to design, analysis and conceptualizes the work. Olga Vorobyova and Elizaveta Grubova have made the contribution to physicochemical experiments. Nadezhda Plotnikova, Olga Deryabina, Anna Solovyeva and Kseniya Belyaeva have made the contribution to biological activity assay. All authors read manually and approved the final manuscript.

\section{CONFLICTS OF INTERESTS}

The authors declare no conflict of interest.

\section{REFERENCES}

1. Kaur M, Yadav R. Pharmacognostic, ethnopharmacological, phytochemical and pharmacological profile of wild guava i.e. Careya arborea Roxb. Int J Curr Pharm Res 2017;9:1-7.

2. Perez J, Shen C-chang, Ragasa CY. Triterpenes from Ceriops decandra (Griff.) W. Theob. AJPCR 2017;10:244-6.

3. Evanjaline M, Vr M. Determination of bioactive components of Caralluma umbellata haw. (Apocynaceae) by gas chromatography and mass spectroscopy analysis. AJPCR 2018;11:194-9.

4. Hordyjewska A, Ostapiuk A, Horecka A. Betulin and betulinic acid in cancer research. J Pre-Clin Clin Res 2018;12:72-5.

5. Periasamy G, Teketelew G, Gebrelibanos M, Sintayehu B, Gebrehiwot M, Karim A, et al. Betulinic acid and its derivatives as an anti-cancer agent: a review. Arch Appl Sci Res 2014;6:4758.

6. Bishayee A, Ahmed S, Brankov N, Perloff M. Triterpenoids as potential agents for the chemoprevention and therapy of breast cancer. Front Biosci (Landmark Ed) 2011;16:980-96.

7. Parikh NR, Mandal A, Bhatia D, Siveen KS, Sethi G, Bishayee A. Oleanane triterpenoids in the prevention and therapy of breast cancer: current evidence and future perspectives. Phytochem Rev 2014;13:793-810.

8. Wei J, Liu H, Liu M, Wu N, Zhao J, Xiao L, et al. Oleanolic acid potentiates the antitumor activity of 5-fluorouracil in pancreatic cancer cells. Oncol Rep 2012;28:1339-45.

9. Yamai H, Sawada N, Yoshida T, Seike J, Takizawa H, Kenzaki K, et al. Triterpenes augment the inhibitory effects of anticancer drugs on the growth of human esophageal carcinoma cells in vitro and suppress experimental metastasis in vivo. Int J Cancer 2009;125:952-60.

10. Vorobyova O, Deryabina O, Malygina D, Plotnikova N, Solovyeva A, Belyaeva K, et al. Betulin-3,28-diphosphate as a component of combination cytostatic drugs for the treatment of Ehrlich ascites carcinoma in vitro and in vivo experiments. Sci Pharm 2018;86:17.

11. Strazhev SV, Berezantsev AY, Karandeeva TV, Drobyazko AA. The use of hydrazine sulfate in the optimization of palliative medical therapy and improvement of quality of life in cancer patients. Oncol Coloproctol 2014;2:13-7.

12. Longley DB, Harkin DP, Johnston PG. 5-fluorouracil: mechanisms of action and clinical strategies. Nat Rev Cancer 2003;3:330-8.

13. Zheng J. Energy metabolism of cancer: glycolysis versus oxidative phosphorylation (Review). Oncol Lett 2012;4:1151-7.

14. Kislitsyn AN, Trofimov AN, Patlasov VP, Chuprova VA. Pat. 2150473 Russian Federation, C07J53/00. Method of betulinol diacetate preparing [Text]. State Unitary Enterprise Central 
Research and Design Institute of the Wood Chemical Industry; 2020.

15. Melnikova N, Burlova I, Kiseleva T, Klabukova I, Gulenova M, Kislitsin A, et al. A practical synthesis of betulonic acid using selective oxidation of betulin on aluminum solid support. Molecules 2012;17:11849-63.

16. Mihara M, Uchiyama M. Determination of malonaldehyde precursor in tissues by thiobarbituric acid test. Anal Biochem 1978;86:271-8.

17. Sirota TV. A new approach to the investigation of adrenaline autooxidation and its application for the determination of superoxide dismutase activity. Biochem (Moscow) Suppl Series B: Biomed Chem 1999;45:263-72.

18. Soloveva AG, Zimin YV. A new way to assess the dynamics of blood metabolism in patients with thermal trauma. Mod Technol Med 2012;2:116-7.

19. Waterborg JH, Matthews HR. The Lowry method for protein quantitation. Methods Mol Biol 1994;32:1-4.

20. Begemann H, Rastetter J. Staining methods. In: Begemann H, Rastetter J. editors. Atlas of clinical haematology. Berlin, Heidelberg: Springer; 1972. p. 9-12.

21. Rajeshwar Y, Gupta M, Mazumder UK. Antitumor activity and in vivo antioxidant status of Mucuna pruriens (Fabaceae) seeds against Ehrlich ascites carcinoma in swiss albino mice. Iranian J Pharmacol Ther 2005;4:46-53.

22. Hossain E, Chakroborty S, Milan A, Chattopadhyay P, Mandal $\mathrm{SC}$, Gupta JK. In vitro and in vivo antitumor activity of a methanol extract of Dregea volubilis leaves with its antioxidant effect. Pharm Biol 2012;50:338-43.

23. Gnanaraja R, Veeru P, Mahendra V. Antitumor activity and in vivo antioxidant status of T. Purpurea against dena induced hepatocellular carcinoma in swiss albino mice. Indian J Sci Res 2014;9:22-7.

24. Sivakumar P, Sambath Kumar R, Sivakumar T, Nethaji R, Vijayabaskaran M, Perumal P, et al. Antitumor and antioxidant activities of Triumfetta Rhomboidea against dalton's ascites lymphoma bearing swiss albino mice. Res J Med Sci 2008;2:203-8.

25. Sun Y, Oberley LW, Elwell JH, Sierra Rivera E. Antioxidant enzyme activities in normal and transformed mice liver cells. Int J Cancer 1989;44:1028-33.

26. Christova T, Gorneva G, Taxirov S, Setchenska M. Effect of 5fluorouracil and cobalt chloride on antioxidant enzymes and heme oxygenase in the livers of Lewis lung carcinoma-bearing mice. C R Acad Bulg Sci 2003;56:93-8.

27. Selvendiran K, Singh JP, Krishnan KB, Sakthisekaran D. Cytoprotective effect of piperine against benzo[a]pyrene induced lung cancer with reference to lipid peroxidation and antioxidant system in swiss albino mice. Fitoterapia 2003;74:109-15.

28. Gold J. Inhibition of gluconeogenesis at the phosphoenolpyruvate carboxykinase and pyruvate carboxylase reactions, as mean cancer chemotherapy. Oncology 1974;29:74-89. 